\title{
Estimation of corrosion resistance of modifying concrete in a solution of sulfuric acid
}

\author{
Oleksii Kabus, Yulyia Kolomiiets", and Viktoriia Lykhohrai \\ Kharkiv National University of Civil Engineering and Architecture, Sumska st. 40, 61002 Kharkiv, \\ Ukraine
}

\begin{abstract}
This study presents the test results of 8 concrete series in 5\% sulfuric acid solution for 28, 56 and 180 days. Each series was made using two mixtures based on CEM II/A-S 32.5 and CEM III/A 32.5 cements. Modification of the properties of concrete was obtained by the introduction of superplasticizer, silica fume, complex of structure modifier and hydrophobic admixture. The water-binder ratio varied from 0.27 to 0.63 , the compressive strength was 26 to $83 \mathrm{MPa}$, and water absorption from 3.4 to $8.4 \%$. Samples of test cubes $(10 \times 10 \times 10 \mathrm{~cm})$ and test beam $(16 \times 4 \times 4 \mathrm{~cm})$ were prepared to immersion in the acid solution. The assessment of corrosion resistance was carried out on the weight loss and strength of concrete in relation to the initial value of 28 days. The obtained results showed that the surface layer of concrete in all samples was destroyed after 28 days of exposure. The deterioration of the corrosion resistance of modified concrete in relation to ordinary concrete without additives was observed regardless of the type of cement. An exception was a series of concrete, which had a water-binder ratio of $0.27-0.28$ and a compressive strength of $77-83 \mathrm{MPa}$.
\end{abstract}

\section{Introduction}

In Ukraine, sewer tunnels, most of which were constructed 40-50 years ago from ordinary concrete $(\mathrm{C} 16 / 20, \mathrm{C} 20 / 25)$, are in the bad or emergency condition now. This has been caused by the intensive impact of destructive factors, among which the influence of sulfuric acid of biogenic origin is most significant [1, 2]. Restoration of their operational characteristics to extend the trouble-free life of the service is an expense and difficult problem. It can be solved by modern cement concretes, which are used for repair work, with different technical and economic efficiency. Note that acid corrosion is unavoidable, because the cement-based concrete is alkaline in nature, and decomposes under an acid environment. However, improving the concrete mixture design is still a viable method because it changes the rate of the corrosion reaction process [3].

Modification of properties of concrete with chemical and mineral additives is a common focus of many studies [3-9]. The introduction of chemical admixtures that are aimed at reducing the permeability of concrete according to DSTU B V.2.6-145: 2010 [10] is one of the main ways to reduce the aggressiveness of the environment to concrete. The use of

* Corresponding author: spoonyla@,gmail.com 
active and pozzolanic mineral additives according to [3, 8, 9] allows to obtain more stable hydrates to sulfuric acid exposure. In the review [3] the authors draw attention to the fact, that the reduced porosity does not guarantee a better acid resistance of concrete and some studies observed opposite results of pozzolan addition effectiveness on acid resistance owing to variations in experimental conditions and the chemical composition of differently sourced pozzolans. Therefore, the chemical compositions of pozzolans should be individually examined, and experimental conditions should be mimicked as close as possible to the real sewer conditions before using it in an actual sewer. As a result of many years of laboratory and field tests, the author [7] also came to the conclusion that concrete additives in highly aggressive environments do not allow to provide the necessary durability of concrete without the use of secondary protection. The investigation of this issue with the testing of concrete in a wide range of their physical and mechanical properties is topical.

One of the simplified methods for assessing the corrosion resistance of concrete for sewer is their laboratory test in solutions of sulfuric acid. This allows, under certain conditions, at the first stage of research to fairly accurate [11] assess the effectiveness of prescription solutions in the development of new compositions of concrete.

The purpose of this study was to evaluate the possibility to improve the corrosion resistance of concrete to the action of solutions of sulfuric acid through the application of complex additives of different principles and mechanisms of action. The total duration of concrete samples exposure under aggressive conditions was 180 days. The obtained results will allow next research directions on the development of effective composite materials for the restoration of sewer structures.

\section{Materials and methods}

The materials used to produce the 8 series with 16 concrete mixes (Table 1). There are two types of cement (CEM II/A-S 32.5 and CEM III/A 32.5), granite crushed stone (5-10 mm in size), fine quartz sand, tap water and highly effective modifying additives (usually used to reduce porosity and increase the corrosion resistance of concrete) were in concrete mixtures composition. The following were applied:

- superplasticizer on polycarboxylate basis for the production of ready-mix concrete (A1);

- mineral pozzolanic additive - highly dispersed silica fume from waste from a local ferroalloy plant (A2);

- colmatizing additive - portland cement and various active, proprietary chemicals. These active chemicals react with the moisture in fresh concrete and with the by-products of cement hydration to cause a catalytic reaction, which generates a non-soluble crystalline formation throughout the pores and capillary tracts of the concrete (A3);

- hydrophobic waterproofing admixture - water solution of potassium methyl siliconat (A4).

The optimal concentrations of additives were chosen taking into account their effect on concrete hardening and compatibility with cements [12]. The consumption of components is based on the actual density of concrete mixtures. The I-VII series were made from highworkability concrete mixes, and the VIII series from a dry-concrete mix. All series except VII had an approximate consumption of binder $400 \mathrm{~kg} / \mathrm{m} 3$, and the VII series $-600 \mathrm{~kg} / \mathrm{m} 3$ of concrete.

According to the requirements of DSTU B V.2.7-213: 2009 [13] and DSTU B V.2.6181: 2011 [14], the concentration of acid in which the test is conducted is not regulated and should be selected depending on the operation conditions of the structure. In the study of the effect of sulfuric acid on the corrosion rate of cement stone and concrete, its values are 
taken in the range from $0.01 \%$ to $10 \%[3-5,15,16]$. Proceeding from the fact that on the concrete surfaces of sewer tunnels the concentration of sulfuric acid can reach several percent, for research purposes its value was selected according to ASTM C267-01 [16] and was equal to $5 \%$.

Table 1. Concrete mix proportions.

\begin{tabular}{|c|c|c|c|c|c|c|c|c|c|c|}
\hline \multirow[b]{2}{*}{ Series } & \multirow[b]{2}{*}{ Mixes } & \multicolumn{2}{|c|}{ Cement } & \multirow{2}{*}{$\begin{array}{c}\text { Coarse } \\
\text { aggregate } \\
\left(\mathrm{kg} / \mathrm{m}^{3}\right)\end{array}$} & \multirow{2}{*}{$\begin{array}{c}\text { Fine } \\
\text { aggregate } \\
\left(\mathrm{kg} / \mathrm{m}^{3}\right)\end{array}$} & \multirow[b]{2}{*}{$\begin{array}{c}\text { Water } \\
\left(\mathrm{kg} / \mathrm{m}^{3}\right)\end{array}$} & \multirow[b]{2}{*}{$\begin{array}{c}\mathrm{W} / \mathrm{C} \\
(\mathrm{W} / \mathrm{B})\end{array}$} & \multirow{2}{*}{$\begin{array}{c}\text { Slump, } \\
\text { cm } \\
\text { (Vebe, } \\
\text { s) }\end{array}$} & \multicolumn{2}{|c|}{ Admixtures } \\
\hline & & type & $\mathrm{kg} / \mathrm{m}^{3}$ & & & & & & designations & $\mathrm{kg} / \mathrm{m}^{3}$ \\
\hline \multirow[b]{2}{*}{ I } & 1 & $\begin{array}{c}\text { CEM } \\
\text { II }\end{array}$ & 397 & 1041 & 744 & 247 & 0.62 & 20 & - & - \\
\hline & 2 & $\begin{array}{c}\text { CEM } \\
\text { III }\end{array}$ & 391 & 1026 & 733 & 245 & 0.63 & 20 & - & - \\
\hline \multirow{2}{*}{ II } & 3 & \begin{tabular}{|c|} 
CEM \\
II
\end{tabular} & 397 & 1043 & 745 & 205 & 0.52 & 19 & A1 & 6 \\
\hline & 4 & \begin{tabular}{|c|} 
CEM \\
III
\end{tabular} & 397 & 1043 & 745 & 199 & 0.5 & 26 & Al & 6 \\
\hline \multirow{2}{*}{ III } & 5 & \begin{tabular}{|c|} 
CEM \\
II
\end{tabular} & 403 & 1057 & 755 & 192 & 0.48 & 25 & Al & 8.1 \\
\hline & 6 & $\begin{array}{c}\text { CEM } \\
\text { III }\end{array}$ & 404 & 1061 & 758 & 184 & 0.46 & 26 & Al & 8.1 \\
\hline \multirow{4}{*}{ IV } & \multirow{2}{*}{7} & CEM & \multirow{2}{*}{366} & \multirow{2}{*}{1044} & \multirow{2}{*}{746} & \multirow{2}{*}{175} & \multirow{2}{*}{$\begin{array}{c}0.48 \\
(0.44)\end{array}$} & \multirow{2}{*}{21} & A1 & 8 \\
\hline & & II & & & & & & & $\mathrm{A} 2$ & 31.8 \\
\hline & \multirow{2}{*}{8} & \multirow{2}{*}{$\begin{array}{c}\text { CEM } \\
\text { III }\end{array}$} & \multirow{2}{*}{364} & \multirow{2}{*}{1037} & \multirow{2}{*}{741} & 160 & 0.46 & ?2 & $\mathrm{A} 1$ & 7.9 \\
\hline & & & & & & 108 & $(0.42)$ & 22 & $\mathrm{~A} 2$ & 31.6 \\
\hline & & & & & & & & & $\mathrm{A} 1$ & 8 \\
\hline & 9 & $\begin{array}{c}\text { CEM } \\
\text { II }\end{array}$ & 368 & 1050 & 750 & 178 & \begin{tabular}{|c}
0.48 \\
$(0.44)$
\end{tabular} & 23 & $\mathrm{~A} 2$ & 32 \\
\hline $\mathrm{V}$ & & & & & & & & & $\mathrm{A} 3$ & 4 \\
\hline & & & & & & & & & $\mathrm{A} 1$ & 7.9 \\
\hline & 10 & CEM & 363 & 1037 & 741 & 171 & $\begin{array}{c}0.47 \\
(0.43)\end{array}$ & 22 & $\mathrm{~A} 2$ & 31.6 \\
\hline & & & & & & & & & A3 & 4 \\
\hline & & & & & & & & & $\mathrm{A} 1$ & 7.8 \\
\hline & 11 & CEM & 360 & 1028 & 734 & 174 & 0.48 & 24 & $\mathrm{~A} 2$ & 31.3 \\
\hline & 11 & II & 500 & 1020 & 134 & $1 / 4$ & $(0.44)$ & 24 & A3 & 3.9 \\
\hline VI & & & & & & & & & A4 & 0.8 \\
\hline$\sqrt{1}$ & & & & & & & & & $\mathrm{~A} 1$ & 7.8 \\
\hline & 12 & CEM & 359 & 1024 & 731 & 168 & 0.47 & 23 & $\mathrm{~A} 2$ & 31.2 \\
\hline & 12 & III & 359 & 1024 & 131 & 168 & $(0.43)$ & 23 & $\mathrm{~A} 3$ & 3.9 \\
\hline & & & & & & & & & A4 & 0.8 \\
\hline & & & & & & & & & $\mathrm{A} 1$ & 12.1 \\
\hline & 13 & CEM & 558 & 1062 & 587 & 167 & $\begin{array}{c}0.3 \\
(028)\end{array}$ & 26 & $\mathrm{~A} 2$ & 48.5 \\
\hline VU & & & & & & & & & A3 & 6.1 \\
\hline VII & & & & & & & & & $\mathrm{A} 1$ & 12.1 \\
\hline & 14 & CEM & 557 & 1059 & 585 & 163 & $\begin{array}{c}0.29 \\
0.27)\end{array}$ & 27 & A2 & 48.4 \\
\hline & & & & & & & & & A3 & 6.1 \\
\hline & & & & & & & & & $\mathrm{A} 1$ & 8 \\
\hline & 15 & CEVI & 370 & 1407 & 553 & 117 & $\begin{array}{c}0.32 \\
(0.29)\end{array}$ & $(30 \mathrm{~s})$ & $\mathrm{A} 2$ & 32.2 \\
\hline VIII & & & & & & & & & $\mathrm{A} 3$ & 4 \\
\hline VIIII & & & & & & & & & $\mathrm{A} 1$ & 8 \\
\hline & 16 & CEM & 370 & 1407 & 553 & 117 & \begin{tabular}{|c}
0.32 \\
$(029)$
\end{tabular} & $\begin{array}{c}0 \\
(30 \mathrm{~s})\end{array}$ & $\mathrm{A} 2$ & 32.2 \\
\hline & & & & & & & & & A3 & 4 \\
\hline
\end{tabular}


Samples of test cubes $(10 \times 10 \times 10 \mathrm{~cm})$ and test beam $(16 \times 4 \times 4 \mathrm{~cm})$ were made according to the standard method and maintained for 28 days under normal conditions. Then some samples were taken to determine the compressive strength, flexural strength and concrete water absorption by weight. Other samples were immersed in a $5 \%$ solution of sulfuric acid (Fig. 1, a) and take out at 28, 56 and 180 days. The concentration of acid solution was controlled by its density. When it was reduced, the required amount of acid was added to reach the initial value of the density of the solution. In each of the required period, two samples were taken from the solution to remove the destroyed concrete layer with a brush (Fig. 1, b). They were then weighed, photographed, tested for strength and found $\mathrm{pH}$. Two different probes sample to determine the $\mathrm{pH}$. First probe selected from the surface and second probe selected from the inside (not less than $1 \mathrm{~cm}$ from the edge of the sample), and then $\mathrm{pH}$ of the water extract was detected using the indicator.

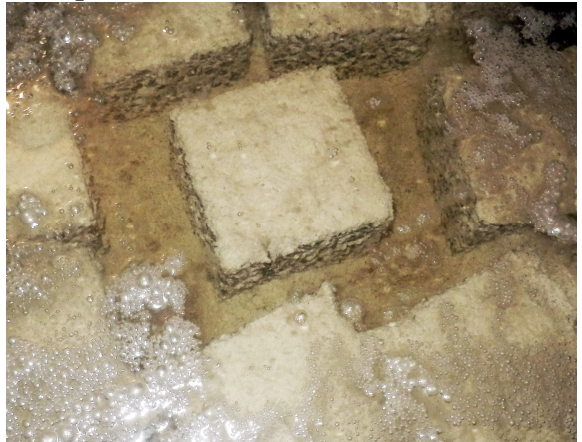

a)

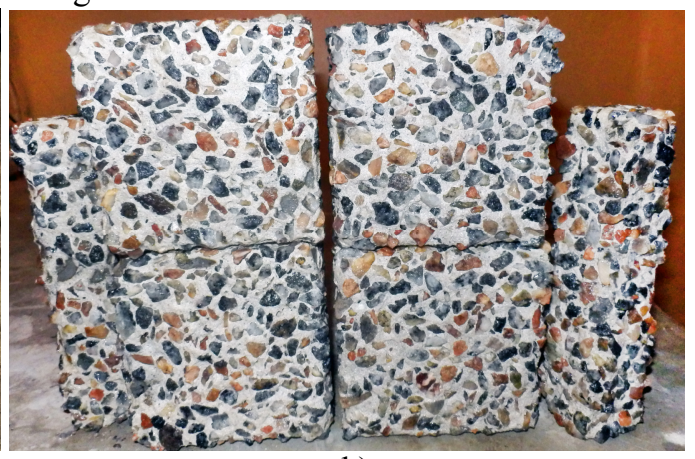

b)

Fig. 1. Samples after exposure in a solution of sulfuric acid: $a$ - exposure in acid solution; $b$-after cleaning the destroyed layer.

\section{Results and discussion}

Water absorption of concrete samples by weight $(\mathrm{Wm})$ in 28 days is given in Table 2. Additive modifiers have reduced the water absorption by 2-2.5 times. The greatest effect of reducing water absorption was achieved by the introduction of superplasticizer, which allowed reducing the amount of water and water-binder ratio (W/B). All other additives did not have a significant effect on the water absorption of concrete. A more significant decrease in water absorption was observed in concrete made at CEM III/A 32.5.

Table 2. Water absorption of concrete.

\begin{tabular}{|c|c|c|c|c|c|c|c|c|c|c|c|c|c|c|c|c|}
\hline Mixes & 1 & 2 & 3 & 4 & 5 & 6 & 7 & 8 & 9 & 10 & 11 & 12 & 13 & 14 & 15 & 16 \\
\hline $\mathrm{W}_{\mathrm{m}}, \%$ & 8.1 & 8.4 & 7.2 & 6.9 & 5.8 & 5.8 & 6 & 5.5 & 5.6 & 5.2 & 5.7 & 4.8 & 3.9 & 3.4 & 4 & 3.4 \\
\hline
\end{tabular}

In all samples, irrespective of the type of cement, composition, strength and water absorption, a total destruction of the surface layer of concrete was observed for 28 days. The mass loss of test cube samples ranged from 3.6 to $6.6 \%$, and the test beam samples $9.2-16.3 \%$ (Table 3 ). In 56 days $-7.2-12.6 \%$ and $16.8-32.8 \%$, and in 180 days $-11.8-$ $22.5 \%$ and $21.7-50.3 \%$, respectively. The overall dimensions of the specimens decreased by $5-10 \mathrm{~mm}$ in 180 days, which corresponds to a corrosion rate of 5-10 $\mathrm{mm} / \mathrm{year}$. In the test beams, the mass loss was 2-2.5 times larger than in test cubes, which is explained by a large 1.9 times the coefficient of open surface. Therefore, for accelerated determination of corrosion resistance of concrete, test beams are more appropriate. It should be understood that, in addition to the size of the samples, the conditions of exposure can greatly affect the results obtained. For example, with constant circulation of acid solution, there is an increase in the rate of corrosion [17]. 
The type of cement did not have a significant effect on the weight loss of the samples, i.e. the increase in the slag additive does not increase the stability of concrete in these conditions. Increasing the strength of samples in 1.5-3 times (Table 4) and reducing water absorption also did not allow to improve the stability of concrete. On the contrary, it was possible to observe somewhat more mass loss in a series of samples with additives. The exception was series VII with high cement content. Its compressive strength was 76.7 82.5 $\mathrm{MPa}$ and the ratio of W/B was $0.27-0.28$. The weight loss of series VII after 56 days of exposure was less than in series I, especially after 180 days. However, it can not be clearly stated that reducing concrete insight and reducing W/B to 0.27 can improve the stability of concrete, because this effect was not observed in series VIII. According to studies [9, 17], the reduction of W/B leads to deterioration of corrosion resistance. In the paper [9], an increase in the mass loss of samples was observed with a decrease in W/B from 0.45 to 0.25 , and in [17], the change in W/B from 0.65 to 0.35 resulted in an increase the erosion depth of concrete. This is explained by the fact that concrete with a high water cement ratio has a higher capacity to absorb the expansion of production reaction of gypsum than that with a low water cement ratio [17].

Comparison of series III-VI, which had approximately equal W/B (0.43-0.48), allows us to state that the addition of silica fume, colmatizing and hydrophobic additives at selected concentrations is absolutely ineffective. Thus, the authors' assertion [3] confirms that the effectiveness of mineral additives needs to be checked in each case. In general, it can be concluded that the corrosion rate of concrete is very high for all series of samples, because according to the requirement of DSTU B V.2.7-213: 2009 [13], the weight loss of chemical-resistant concrete in one year of immersion test should not exceed $1 \%$.

Table 3. Loss of concrete samples mass after immersion in $5 \%$ solution of sulfuric acid.

\begin{tabular}{|c|c|c|c|c|c|c|c|}
\hline \multirow{2}{*}{ Series } & \multirow{2}{*}{ Mixes } & \multicolumn{6}{|c|}{ Mass loss, $\%$} \\
\cline { 3 - 8 } & & \multicolumn{3}{|c|}{ test cubes } & \multicolumn{3}{c|}{ test beams } \\
\cline { 3 - 8 } I & 1 & 3.6 & 9.0 & 15.8 & 10.4 & 21.9 & 41.7 \\
\cline { 2 - 8 } & 2 & 3.6 & 8.6 & 17.6 & 9.2 & 23.8 & 41.7 \\
\hline \multirow{2}{*}{ II } & 3 & 5.0 & 12.2 & 20.2 & 11.3 & 28.8 & 42.2 \\
\cline { 2 - 8 } & 4 & 5.0 & 10.8 & 20.9 & 13.2 & 20.5 & 43.3 \\
\hline \multirow{2}{*}{ III } & 5 & 5.6 & 12.3 & 19.0 & 10.5 & 28.6 & 38.8 \\
\cline { 2 - 8 } & 6 & 5.7 & 9.1 & 17.6 & 15.0 & 26.8 & 40.6 \\
\hline \multirow{2}{*}{ IV } & 7 & 6.3 & 11.6 & 21.0 & 12.0 & 28.2 & 43.8 \\
\cline { 2 - 8 } & 8 & 6.6 & 11.7 & 21.5 & 16.3 & 31.2 & 48.1 \\
\hline \multirow{2}{*}{ V } & 9 & 6.0 & 12.1 & 20.9 & 12.9 & 29.0 & 41.9 \\
\cline { 2 - 8 } & 10 & 6.1 & 11.4 & 21.0 & 14.5 & 32.8 & 48.9 \\
\hline \multirow{2}{*}{ VI } & 11 & 6.3 & 10.8 & 21.5 & 13.5 & 28.8 & 44.0 \\
\cline { 2 - 8 } & 12 & 6.7 & 12.6 & 22.5 & 15.8 & 30.0 & 50.3 \\
\hline \multirow{2}{*}{ VII } & 13 & 4.5 & 8.5 & 12.0 & 10.2 & 16.8 & 21.7 \\
\cline { 2 - 8 } & 14 & 4.3 & 7.2 & 11.8 & 12.9 & 19.3 & 23.8 \\
\hline \multirow{2}{*}{ VIII } & 15 & 5.7 & 10.0 & 20.6 & 12.6 & 25.1 & 43.0 \\
\cline { 2 - 8 } & 16 & 5.1 & 9.2 & 21.2 & 13.5 & 31.5 & 46.6 \\
\hline
\end{tabular}

The loss of strength of concrete samples as a result of corrosion was more significant than loss of mass. The compressive strength of the samples decreased by $19-46 \%$ after 28 days and 39-63\% after 56 days of exposure (Table 4). Flexural strength changed 
differently. There was an increase in strength up to $39 \%$ in samples $1,6,13$, while in other samples, it was reduced up to $62 \%$ for 28 days. After 56 days a compressive and flexural strength were reduced on $39-63 \%$ and $9-61 \%$ respectively. The correlation between compressive strength and flexural strength was not observed, the results were random. For example, sample 13 had a reduction in compressive strength of $38 \%$ and an increase in flexural strength by $39 \%$. Proceeding from this, in 180 days, the strength of concrete was not determined. This kind of change in the strength of concrete, in our opinion, is associated with uneven transfer of load on the surface of samples with a bare coarse aggregates (Fig.1, b). Internal concrete did not undergo visual changes (Fig. 2), so all concrete of the samples could not change a strength so much. The absence of corrosion of the internal concrete of the sample holds the value of the $\mathrm{pH}$ of the water extract, which on the surface was equal to $3-5$, and the inside was 12 for all samples.

Table 4. Change in the strength of concrete samples after immersion in 5\% solution of sulfuric acid.

\begin{tabular}{|c|c|c|c|c|c|c|c|}
\hline \multirow{3}{*}{ Series } & \multirow{3}{*}{ Mixes } & \multicolumn{2}{|c|}{ Initial strength, MPa } & \multicolumn{4}{|c|}{ Strength loss, \% } \\
\hline & & \multirow{2}{*}{\begin{tabular}{|c} 
compressive \\
strength
\end{tabular}} & \multirow{2}{*}{$\begin{array}{l}\text { flexural } \\
\text { strength }\end{array}$} & \multicolumn{2}{|c|}{28 days } & \multicolumn{2}{|c|}{56 days } \\
\hline & & & & $\begin{array}{l}\text { compressive } \\
\text { strength }\end{array}$ & $\begin{array}{l}\text { flexural } \\
\text { strength }\end{array}$ & $\begin{array}{l}\text { compressive } \\
\text { strength }\end{array}$ & $\begin{array}{l}\text { flexural } \\
\text { strength }\end{array}$ \\
\hline \multirow{2}{*}{ I } & 1 & 26.4 & 4.6 & 19.2 & -18.8 & 38.6 & 14.9 \\
\hline & 2 & 26.1 & 5.0 & 22.6 & 26.4 & 43.3 & 34.5 \\
\hline \multirow{2}{*}{ II } & 3 & 38.2 & 7.0 & 35.2 & 19.3 & 52.3 & 31.5 \\
\hline & 4 & 39.5 & 5.7 & 36.9 & 6.8 & 58.3 & 26.4 \\
\hline \multirow{2}{*}{ III } & 5 & 44.1 & 7.5 & 36.5 & 3.1 & 53.8 & 50.3 \\
\hline & 6 & 50.0 & 7.0 & 37.7 & -1 & 48.7 & 40.4 \\
\hline \multirow{2}{*}{ IV } & 7 & 44.7 & 7.3 & 34.5 & 12.4 & 53.2 & 45.1 \\
\hline & 8 & 46.5 & 6.3 & 46.1 & 19.9 & 60.1 & 38.2 \\
\hline \multirow{2}{*}{ V } & 9 & 48.9 & 8.4 & 33.6 & 10.2 & 55.1 & 46 \\
\hline & 10 & 48.2 & 7.5 & 35.4 & 7.7 & 53.4 & 43.4 \\
\hline \multirow{2}{*}{ VI } & 11 & 45.9 & 7.8 & 31.3 & 26.3 & 56.4 & 40.2 \\
\hline & 12 & 51.8 & 8.6 & 37.2 & 316 & 62.7 & 46.3 \\
\hline \multirow{2}{*}{ VII } & 13 & 76.7 & 8.2 & 37.9 & -39.4 & 57.2 & 10 \\
\hline & 14 & 82.5 & 8.7 & 35.8 & 14.5 & 48.2 & 9.4 \\
\hline \multirow{2}{*}{ VIII } & 15 & 64.6 & 9.0 & 36.6 & 62 & 49.0 & 60.9 \\
\hline & 16 & 62.5 & 8.7 & 32.7 & 32.7 & 43.6 & 55.7 \\
\hline
\end{tabular}

According to $[15,17]$, there are three distinct layers of concrete: the first is a friable surface layer of fully corroded that has no strength, the second - is a thin layer of concrete in a few mm, which has some strength, and the third - the inner concrete in which there is no deep or selective destruction. For a more accurate determination of the concrete strength in the study [9] the surface was aligned with cement mortar of the ratio 1:3. This made it possible to obtain more precise dependencies of concrete durability over time, the value of which for 180 days for various concrete mixes was from 20 to $45 \%$. But, in our opinion, this method of preparing samples should not be considered sufficiently reliable. To obtain accurate results, it is necessary to completely remove the second layer of concrete and prepare the surface of the samples prior to testing in accordance with the standard requirements. An alternative method for analyzing the concrete strength can be to determine the tensile strength when splitting the test cubes (Fig. 2, a.). In this case, the influence of the surface of the samples should not be significant. 


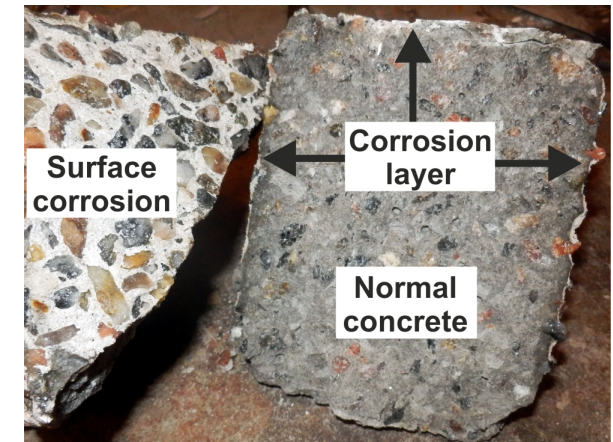

a)

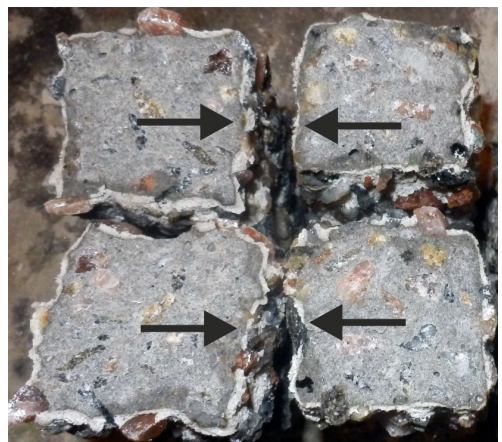

b)

Fig. 2. The appearance of concrete samples after the tensile test: $a$ - split test of cubes; $b$ - flexural strength test of beams

The obtained results show that the method for determining mass loss is more correct than the method of determining the strength of concrete. Authors [8] weight loss measurement was identified as a proper test method for indicating durability of concrete against sulfuric acid attack. However, authors [9] when testing in a less concentrated solution (1\%) believe that mass loss alone is not a reliable index to measure the durability of concrete in acid attack and must be supplemented by strength studies.

\section{Conclusions}

At present, in the world there is no single method for determining the resistance of concrete to the action of solutions of sulfuric acid, which significantly affect the results obtained by different researchers. The most important factors are the concentration of the acid solution, the immersion test conditions and the size of the samples. Special attention is required to the method of determining the strength of concrete, which has a damaged top layer. The conducted studies have shown that the selected additives do not allow to significantly changes of the resistance of concrete on ordinary cements to the action of $5 \%$ solution of sulfuric acid. Increasing the strength, reducing W/B to 0.3 and reducing the absorption of concrete by $2-3$ times is not effective. Further tests require concrete with a value of W/B ration of less than 0.25 and more than 0.65 .

\section{References}

1. A. Garmash, D. Bondarenko, G. Zubko, D. Goncharenko. World Journal of Engineering, 1, 72 (2016)

2. D. Bondarenko, V. Bulhakov, A. Garmash, D. Goncharenko, S. Pilihram, Kanalizatsiini tuneli Kharkova: QUO VADIS: monohrafiia (Kharkiv, Rarytety Ukrainy, 2018)

3. L. Wu, C. Hu, W. Liu, Sustainability, 10(2), 517, (Canada, 2018)

4. A. Khodabakhshian, M. Ghalehnovi, J. Brito, E. Shamsabadi, Journal of Cleaner Production, 170, 42 (2018)

5. N.P. Rajamane, M.C. Nataraja, N. Lakshmanan, J.K. Dattatreya \& D. Sabitha, Indian Journal of Engineering \& Materials Sciences, 357, (2012)

6. Z. Makhloufia, M. Bederinaa, M.Bouhichaa, E. Kadrib. Eighth International Conference on Material Sciences. Physics Procedia, 55, 329 (2014). 
7. N. K. Rozental. Beton i zhelezobeton, 2, 78 (2011)

8. A.A. Ramezanianpour, A. Zolfagharnasab, F.B. Zadeh, S.H. High, Tech Concrete: Where Technology and Engineering Meet - Proceedings of the 2017 fib Symposium, 2290 (2017)

9. S. Goyal, M. Kumar, D. S. Sidhu, Journal of Advanced Concrete Technology, 2, 273 (2009)

10. DSTU B V.2.6-145:2010 Zakhyst betonnykh i zalizobetonnykh konstruktsii vid korozii (2010)

11. B. Huber, H.B. Hilbig, J.E. Drewes, E. Müller, Cement and Concrete Research, 1, 36 (2017)

12. A.V. Usherov-Marshak, A.V Kabus. Inorganic Materials, 4, 479 (2016)

13. DSTU B V.2.7-213:2009. Building materials. Chemically resistant concretes. Test methods (2009).

14. DSTU B V.2.6-181:2011. Protection against corrosion of concrete and reinforced concrete constructions. Test methods (2011).

15. V.M. Moskvyna, Korrozyia betona v ahressyvnikh, (Moscow, 1971)

16. ASTM C267-01. Standard Test Methods for Chemical Resistance of Mortars, Grouts, and Monolithic Surfacings and Polymer Concretes (2018).

17. K. Kawai, S. Yamaji, T. Shinmi, 10DBMC International Conférence On Durability of Building Materials and Components, 17 (2005) 